\title{
LOOKING BACK, LOOKING FORWARD
}

\section{Queer History Month, Museums, and Activism for Justice and Freedom}

\author{
Tuula Juvonen and Therese Quinn ${ }^{1}$
}

\section{Getting the Ball Rolling}

LGBT History Month was initiated in the United States by an out schoolteacher named Rodney Wilson in 1994. Raised in a fundamentalist Christian family in the conservative midwestern state, Missouri, Wilson began to study history as he "outgrew" his childhood religion (Wilson, 2015). His investigations took a personal turn as he started a coming out process in his mid-twenties; Wilson explored LGBT history for "meaning, purpose and support" and found that what he learned gave him a "sense of place and potential” (Wilson, 2015). Wilson came out as gay to his high school students after they viewed a film about the Holocaust. This earned him a reprimand from the school's administration, telling him he could only discuss "homosexuality in class if it was part of the existing history curriculum" (Farrow, 1995). This became an opening for Wilson. He was inspired by the successes of previous activists, who fought to see Black, women's, Latinx, Indigenous and other cultural histories acknowledged, to create LGBT History Month (Wilson, 2015; Farrow, 1995). He and a friend began writing a proposal, and with the support of many others,

1 This is a co-written paper with no first author.
LGBT History Month was inaugurated that October (Farrow, 1995; Hemphill, 2015).

The wheel was invented again in 2004 in the United Kingdom by activist and teacher Sue Sanders and other members of Schools Out, a group working to challenge the oppression of LGBT people in the education system, which Sanders co-founded in 1984 (Watters, 2012). Since then the idea has travelled further, and now LHBT history is celebrated as Queer History Month in Berlin, Germany, and as Rainbow History Month in Finland, as just two examples.

This special issue takes these annual celebrations as a starting point to interrogate LGBTQI+ issues around museums and activism, a topic that has during the past year experienced quite a boost. This is evidenced by the vibrant and well-attended Archives, Libraries, Museums and Special Collections (ALMS) conferences, most recently held in Berlin in 2019 on the theme Queering Memory ${ }^{2}$ - and some of the papers included here are the direct outcomes of connections forged at ALMS. Also, several

2 Please note that many of the presentations are available at the Queering Memory conference website https://queeralmsberlin2019.de/interactive-program/.

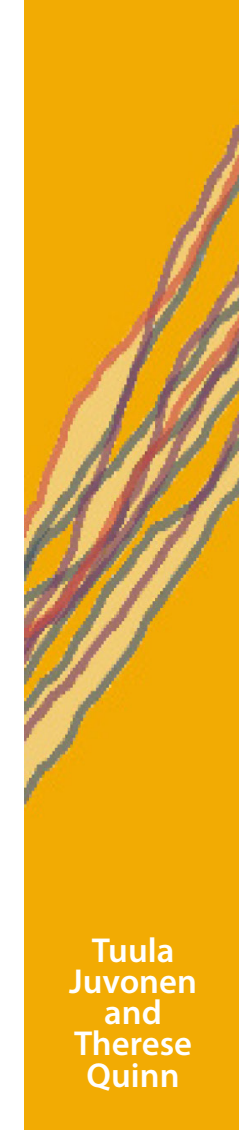


recent interesting publications, included in this journal as reviews, attest to a resurgent interest in linking culture and heritage sites to movements for justice and social change, as of course does on-the-ground organizing and actions by museum workers.

A persistent need for our queer past, and a need to reflect upon the ways it has been provided to us, is evidenced in this special issue. We have included an essay by Sue Sanders, where she recollects not only on her personal path to cocreating LGBTQ+ History Month in the United Kingdom, but also the inventive strategies the group of activists has successfully used to push their agenda and to shift the attitudinal landscape in that country, and beyond. She also describes the struggles forged by UK activists in the Thatcher era, with its repressive take on anything but heteronormativity. This vividly reminds us that the victories won are hard fought, and never come with a guarantee. However, pushing through that difficult time has also taught the activists valuable lessons in organizing that allowed them to use LGBTQ+ History Month as a launchpad for related initiatives in schools, libraries, museums and other sites in the UK, from organizing lectures and programs, and developing a resource-rich website, to using social media to publicize events across the country.

It will likely surprise no one that how well LGBTQI+ history is presented and received is highly dependent on context and location - and the context also plays a role in how different initiatives had gotten off the ground. Unlike in the U.S., where LGBT History Month was introduced in the schools, in the UK and in Finland the activism has expanded in particular in collaboration with museums and archives. Many times, social and institutional norms have compromised queer content in those venues. Rita Paqvalén relates a history of efforts to queer museums in Finland, with three exhibition projects in which she participated with other researchers, artists and museum workers as focal points. These efforts have since led to establishing Rainbow History Month in 2018 and founding an association Friends of Queer History in 2020. This association now carries on and expands the activities initiated by the History Month on their newly launched website. ${ }^{3}$

Clinton Glenn, for his part, follows the "Firsts" in the Baltic region, namely the first queer art and history exhibitions that have taken place there during the mid-2000s. He points out how these have taken up queer politics and themes, and are shaped by resistance to the silencing effects of communism, and both anti-LGBTQ conservatism and a rejection of "western" values. Moreover, the review written by Alexandra Novitskaya about Queer-Feminist Solidarity and the East-West Divide, and edited by Katharina Wiedlack, Saltanat Shoshanova and Masha Godovannaya, provides additional background to the social and political situation that affects queers in the Post-Soviet regions. The anthology, this review notes, offers a rich sampling of perspectives on solidarity efforts between queer and feminist communities in postsocialist Central and Eastern Europe and Eurasia, and in the West.

\section{Doing the Walk}

Activists and cultural workers who aim at a more just society are increasingly successful in pushing memory institutions to do their part of the work, too. Hence this volume includes texts written by practitioners in different memory institutions, who explicate their learning curve in their professional capacity when confronted with issues of queer pasts. Morgan Gieringer and Jaimi Parker, who work at the University of North Texas Special Collections in Dallas, ended up creating several archival exhibitions highlighting queer lives and cultures in a city thus far known

3 https://sateenkaarihistoria.fi/

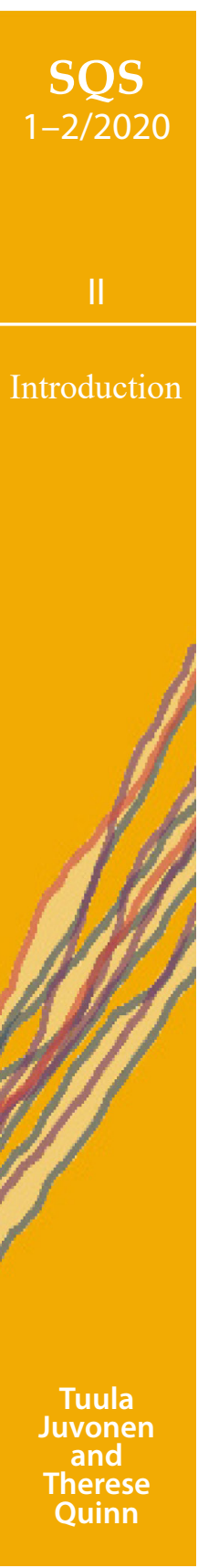


more for its homophobia than being a supportive environment for queer cultural production. The context was rather different for Tom Furber, who works as an Engagement and Learning Officer in London Metropolitan Archives, which has collections dating to 1067 , and queer records from as early as 1395. Furber has well-established queer support groups that serve as "critical friends" - guiding and holding him accountable - as he interprets artifacts related to LGBTQ+ history. These authors also discuss the situation where they themselves are not members of the queer community they serve and reflect interestingly upon that experience and how they have mastered its challenges.

It is vital that practitioners are keeping an eye on the changes that take place in the lives of LGBTQI+, and in the discussions about social justice that are forged in their diverse communities. The recent collection Museums, Sexuality, and Gender Activism edited by Joshua G. Adair and Amy K. Levin, here reviewed by Nina Nyman, provides a plethora of inspiring examples of the activism that has been going on in the museums over the recent years. In this special issue we have included a piece by acclaimed freelancer museum consultant Dan Vo, who adds nuances to that discussion by showing how trans and non-western experiences that already reside in the museum exhibitions can be brought to bear in museums' exhibitions and guided tours.

\section{Who and How Will We Remember?}

When we are talking about history, we are most likely talking about people who are no longer with us. In her dissertation, Varpu Alasuutari introduces readers to her ideas about queer death and the (im)possibilities queers have to remember their loved ones. Especially interesting for this special issue could be her theorizations about the rituals of remembrance as examples of melancholic attachments, or continuing bonds, which can be beneficial in the midst of grief - but also create possibilities for adding to history.

It is also interesting to think who are the people who will be hailed when they are gone. Sometimes they are the very people who have been overlooked during their lifetime, as Leslie Wooden notes. In her essay she introduces us to the archive of a Black photographer from the United States, Alvin Baltrop, who was dedicated to documenting his fellow queers, for example, in the piers of New York - much to dismay of his contemporaries. Yet, since his death in 2004, he has been rediscovered and now enjoys a fame unknown to him during his lifetime.

The best way to ensure posthumous recognition is of course to take the matters in one's own hands. This was done by Kate Charlesworth in her Sensible Footwear: A Girls Guide. Charlesworth drew a comic book about her life - and the lives of her fellow lesbians and gay men in the UK, who belonged to the generation that saw the attitudes change to an unforeseen extent. Her comic autobiography is presented to us in a review by Riikka Taavetti.

\section{Queer Perspectives}

Representation is always a salient topic for cultural sites, but there is also a vibrant strand of discussion taking place about the ways queer approaches can inform professional practices in memory institutions. Interestingly enough, queer feminist approaches feature here in abundance: Pia Laskar in Sweden and Nikki Sullivan in Australia are both queer and gender studies scholars who have moved from the academia to work in the museum field instead - and now challenge their new professional environments with queer interventions. Rita Paqvalén reviews for us the handbook Den outstälda sexualiteten (The Unexhibited Sexuality) Laskar has written for museum professionals, and Sarita Hernández reviews the book Queering

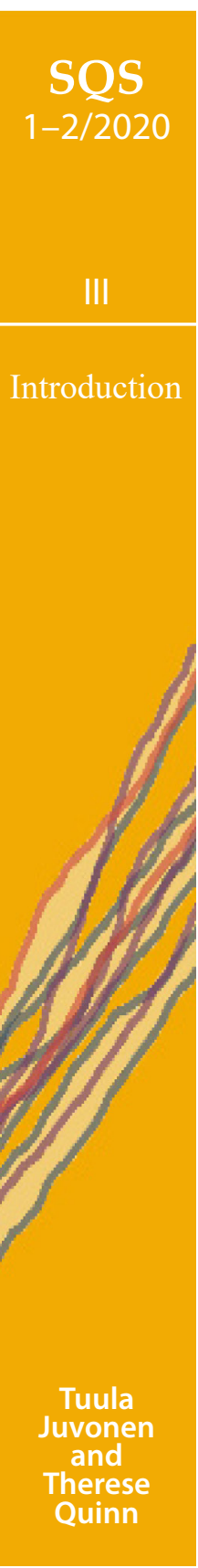


the Museum, which Sullivan co-authored with Craig Middleton. Both books reflect and support the flourishing of queered cultural practices and spaces in museums.

Tuula Juvonen's contribution follows a similar line of thought, as she interrogates the application of queer theory in different LGBTQ+ guided tours provided by art museums belonging to the Finnish National Gallery. She asks how queer theories travel from academia to the museum praxis, and how are they interpreted in that context?

Interpretation is also the key issue in Sukupuolen sotkijat (Gender Confusers), the book written and compiled by the art historian Harri Kalha, reviewed here by Asta Kihlman. Kalha presents in that photo book a collection of anonymous images in postcards and photos he has collected over the years from flea markets. With his queer interpretations of historical material from the beginning of the $20^{\text {th }}$ century he urges us to reconsider the assumed universality and immutability of binary gender conventions.

\section{Are we there yet?}

As many of the entries in this volume attest, the labor in memory institutions is conducted under very different working conditions. Some of the authors have permanent positions in memory institutions, but many of the queer cultural workers have more precarious positions, out of which they try to make a difference. Many of the museum professionals are also in debt to the persistent and innovative work of unpaid activists, who have against all odds pushed through their vision, and thus assisted in queering the museums and the past they present to their visitors. Jemina Lindholm and Kaura Raudaskoski, a collaborative pair of freelance museum workers, pose a critical analysis of memory institutions' treatment of social movements. In their essay they call for institutional accountability, noting that institutions seem more interested in hosting special events and celebrations than in making structural changes essential to supporting queer and crip lives. Where are the ramps and all-gender bathrooms? Inclusion can begin when exclusion is recognized and countered.

LGBT History Month started initially in the schools in the United States, and that is also the location from which many of the examples are drawn in Therese Quinn's book Questions about Museums, Culture and Justice to Explore in Your Classroom, reviewed for us by Rita Paqvalén. In that book Quinn suggests ways teachers can use museums not only to queer their classrooms, but also to bring forward in their teaching an intersectional understanding of social justice.

Museums and schools are powerful sites of learning and engagement. As they increasingly and creatively celebrate queer histories, they also help to set a foundation for more just futures.

We hope you find this special issue inspiring for future research, teaching, and queer history activism, possibly in germinal collaborations with respective communities and memory institutions.

\section{References}

Farrow, C. (1995, January 29). More gay teachers are coming out of closet. The LA Times. Retrieved from: https://www.latimes.com/archives/la-xpm1995-01-29-mn-25614-story.html

Watters, D. (2012, February 13). LGBT heroes - Day 13. Polari Magazine. Retrieved from: http://www.polarimagazine.com/lgbt-history-month/ lgbt-hero-sue-sanders/

Wilson, R. (2015, October 1). Knowing LGBT history is knowing yourself. The Advocate. Retrieved from: https://www.advocate.com/ commentary/2015/10/01/knowing-lgbt-history-knowing-yourself

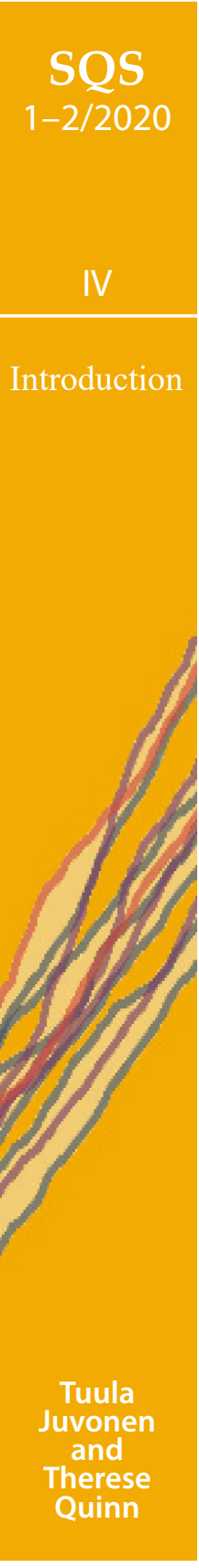

